論文

비정상 패널 및 시간전진 자유후류를 이용한 $\mathrm{BVI}$ 비정상 로터 공력 해석

위성용*, 이덕주**

\title{
An Analysis of BVI Unsteady Rotor Aerodynamics using Unsteady Panel and Time-Marching Free Wake
}

Seong-Yong Wie* and Duck-Joo Lee**

\begin{abstract}
The unsteady panel and time-marching free wake are applied to the rotor aerodynamics and wake behaviour. Numerical results of panel and free wake are compared and validated with experimental data. Using these methods, unsteady rotor aerodynamics in BVI condition is analyzed and discussed in detail.

\section{초 록}

비정상 패널법과 시간 전진 자유 후류법을 연계하여 제자리 및 수직 비행 하는 헬리콥 터 로터의 공력 및 익단와류를 검증하였다. 검증된 수치 방법을 이용하여 저속 하강 비행 하는 로터에서 발생하는 BVI(Blade Vortex Interaction)의 비정상 공력을 해석 하고 이때 나타나는 익단 와류에 의한 공력의 변화를 고찰하였다.
\end{abstract}

Key Words : Helicopter Aerodynamcis(헬리콥터 공기역학), BVI(블레이드-와류 간섭), Unsteady Panel Method(비정상 패널법), Time-Marching Free Wake(시간 전진 자유후류)

\section{I. 서 론}

헬리콥터 로터의 공력, 성능, 진동 특성의 파악 을 위해서는 로터 후류의 정확한 해석이 수행되어 져야 한다. 특히 제자리 비행과 수직비행의 경우 로터 후류의 유도속도에 의한 유입류가 크기 때문 에 후류 효과가 지배적으로 나타난다. 이러한 이 유로 헬리콥터 로터의 해석은 후류의 효과를 어떻 게 잘 모사하는지에 크게 영향을 받게 된다. 로터 해석은 크게 전산유체역학(Computational Fluid Dynamics)을 이용한 방법과 와류를 기반으로 한 자유후류(Free wake)를 통하여 이루어져 왔다. 전산유체역학을 이용한 로터 해석의 경우 유동의

† 2009년 2월 6일 접수 2009년 3월 17일 심사완료

* 정회원, KAIST 항공우주공학과 대학원

** 정회원, KAIST 항공우주공학과

교신저자, E-mail : wsy278@kaist.ac.kr

대전광역시 유성구 구성동 373-1
압축성과 점성에 의한 로터 해석에 유용하다. 또 한 자유후류의 경우 후류 효과가 지배적인 영역 이나 저속비행의 경우에 효율적으로 사용할 수 있다. 위의 두 방법 이외에도 적분방정식을 바탕 으로 한 비정상 패널법 또한 로터 해석에 사용될 수 있다. 특히 자유 후류와의 연계를 통하여 보 다 정확한 로터 공력을 해석 할 수 있다. 비정상 패널법은 블레이드 두께에 의한 공력 변화와 후 류 전진 등을 비교적 빨리 해석 할 수 있기 때문 에 많은 회전수 해석이 가능하고 그에 따른 공력 변화 예측에 유리하다. 또한 후류에 의한 공력 변화가 나타나는 경우 후류 효과를 비교적 자세 히 반영할 수 있다.

본 연구에서는 비정상 패널과 시간전진 자유 후류를 이용하여 후류에 의한 공력 변화 크게 발 생하는 BVI(Blade Vortex Interaction) 비행조건 에서 로터를 해석 하였으며 이때 발생하는 비정 상 공력 변화를 고찰하였다. 


\section{II. 본 론}

\section{1 로터 수치해석 방법}

수직 및 BVI 비행해석을 통한 비정상 하중 예 측을 위하여 본 방법은 포텐셜 기반의 비정상 패 널법과 시간 전진 자유후류법을 이용하여 공력 해석을 수행 하였다. 비정상 패널법은 3 차원 라 플라스 식을 Green 정리를 이용하여 유도한 적분 방정식을 이용하여 다음과 같이 해석되게 된다.

$$
\begin{gathered}
\text { Lapace equation : } \nabla^{2} \phi=0 \\
\int_{S_{B}}\left(\frac{\partial \phi}{\partial n} G-\phi \frac{\partial G}{\partial n}\right) d S-\int_{S_{W}} \Delta \phi \frac{\partial G}{\partial n} d S=0
\end{gathered}
$$

위에서 나타내는 $\phi$ 는 속도 포텐셜을 의미하 며 경계면에서의 포텐셜 수직 변화는 $\frac{\partial \phi}{\partial n}=\overrightarrow{v_{B}} \cdot \vec{n}$ 인 Neumann 경계조건을 통하여 얻 을 수 있으며 경계면의 $\phi$ 는 Dirchlet 경계조건을 이용할 수 있다. 본식을 통하여 속도 포텐셜 $\phi$ 와 비정상 공력을 얻을 수 있다.

수치적으로 위의 지배방정식을 풀기 위해서는 경계의 차분화가 필요하다. 로터 공력 해석에서 는 경계는 블레이드를 의미하게 된다. 블레이드 는 사각 패널로 차분화 되며 블레이드와 후류 부 분으로 나누어서 차분된다. 블레이드는 패널 $\mathrm{M}$ 개 후류는 패널 $\mathrm{N}$ 로 나뉘어서 각 패널에서의 포 텐셜은 대수식으로 표현하면 아래 식과 같다.

$$
\begin{aligned}
\sum_{m=1}^{M} B_{m}(t) \chi_{m} & (t)+\sum_{m=1}^{M} C_{m}(t) \phi_{m}(t) \\
& +\sum_{n=1}^{N} F_{n}(t) \Delta \phi_{n}(t)=0 \\
& \chi_{m}=(\partial \phi / \partial n)_{m} \\
B_{k m}= & \int_{S_{m}} \frac{-1}{4 \pi\left|x-x_{k}\right|} d S \\
C_{k m}= & \int_{S_{m}} \frac{\partial}{\partial n}\left(\frac{1}{4 \pi\left|x-x_{k}\right|}\right) d S \\
F_{k n}= & \int_{S_{n}} \frac{\partial}{\partial n}\left(\frac{1}{4 \pi\left|x-x_{k}\right|}\right) d S
\end{aligned}
$$

블레이드 표면의 포텐셜 크기를 이용하여 블레이 드의 표면 압력을 계산하게 된다. 표면 압력은 비정상 Bernoulli 식을 이용하여 얻게 된다.

$$
\frac{\partial \phi}{\partial t}+\frac{1}{2} v^{2}+\frac{1}{\rho} p=\frac{1}{\rho} p_{r e f}
$$

압축성 영역에서의 압력은 Prandtl-Glauert 보 정을 이용하여 보정하게 된다.

\subsection{1 로터 후류 해석 방법}

블레이드 에어포일 trailing edge에서 발생되는 후류는 더블렛 패널로 모사된다. 더블렛 패널로 모사된 후류는 시간 전진을 하게 되면서 블레이드 익단에서 후류의 강도로 인하여 형상이 왜곡되게 된다. 그러나 일반적인 사각 더블렛 패널은 이러 한 형상 변형을 고려하기 힘들다. 이러한 이유로 후류 더블렛 패널은 와고리 상등(doublet-vortex equivalence)을 이용하여 와고리로 변환 되며 변 환된 와고리는 trailed vortex filament와 shed vortex filament로 다시 표현된다.

$$
\begin{gathered}
\vec{V}_{\text {wake }}=\nabla \phi=-\frac{\mu}{4 \pi} \int_{S_{W}} \nabla \frac{z}{r^{3}} d S \\
=\frac{\Gamma}{4 \pi} \int_{C} \frac{\overrightarrow{d l} \times \vec{r}}{r^{3}} \\
\vec{r}=\left[\left(x-x_{0}\right)^{2}+\left(y-y_{0}\right)^{2}+\left(z-z_{0}\right)^{2}\right]
\end{gathered}
$$

위 식에서 $\mu=\Delta \phi$ 이며 $\Gamma$ 는 폐곡선 $\mathrm{C}$ 내의 와고리의 강도를 나타낸다. 와고리의 강도는 더 블렛 패널의 크기와 같게 된다. 식 (5)에서 보면 알 수 있듯이 더블렛 패널은 후류의 유도속도 계 산을 위하여 표면 적분을 수행해야 하지만 와고 리의 경우 간단한 선 적분을 통하여 얻을 수 있 다. 또한 더블렛과 비교하여 특이성 정도가 적으 며 간단한 해석식으로 표현할 수 있다. 이러한 이유로 더블렛 패널보다 와고리로 상등된 후류가 좀 더 후류 해석에 용이함을 알 수 있다.

일반적인 와선의 경우 직선 형태로 표현된다. 그러나 실제적인 로터 후류의 모양은 나선형의 모양을 갖고 있다. 이러한 이유로 본 방법에서는 직선 와선이 아닌 곡선 와선으로 후류가 모사 되 며 곡선 와선의 경우 후류 형상 뿐 아니라 자기 유도 속도(self induce velocity) 계산이 가능하게 되어 정확한 후류 전진 해석을 할 수 있다. 사용 된 곡선 와선은 parabolic bending interpolation 을 이용하게 된다. Parabolic function 은 곡선 interpolation에 적용된다. Parabolic interpolation 은 비직관적인 접선방향 성분이 아닌 직관적이고 원 형태를 잘 모사하는 접선 성분을 표현할 수 있다. 본 연구에서는 곡선으로 모사된 와선을 일 반적인 Biot-Savart law식이 아닌 식 (6)의 Moore-Rosenhead 식을 이용하여 특이성 해소 및 곡선 형태의 와선의 유도 속도를 계산 하였 다. 
Moore-Rosenhead equation :

$$
\vec{V}=\frac{1}{4 \pi} \int_{C} \frac{\vec{r}}{\left(|\vec{r}|^{2}+\mu_{s}^{2}\right)^{3 / 2}} \times \Gamma \frac{\overrightarrow{\partial y}(\xi, t)}{\partial \xi} d \xi
$$

$\vec{y}(\xi, t)$ 는 곡선 와선 위의 좌표이며, $\mu_{s}$ 는 Rosenhead의 절삭 변수이다. 절삭 변수는 특이 성을 줄이기 위하여 도입되었다. 본 방법에서는 실험값과의 비교하여 절삭 값을 블레이드 코드 길이의 $10 \%$ 로 설정 하였다. 위에서 사용된 interpolation 방법은 trailing edge에서 수직인 trailing vortex filament에만 적용 되었으며 trailing edge에 평행인 shedding 부분은 직선와 선으로 표현되었다. 위의 유도 속도 계산은 후류 의 거동에 사용되어진다.

\section{1 .2 특이성 해소}

후류 패널과 블레이드 패널이 서로 부딪힐 경우 수치적인 특이성이 발생하게 된다. 본 연구에서는 이러한 특이성을 해소하기 위하여 Gennaretti[1]가 제안한 Novel boundary integral approach를 적 용하였다. 본 적분식은 후류 패널에 의한 포텐셜 영향을 주변 속도장을 이용하여 간접적으로 얻는 방법으로 후류패널 포텐셜을 와류에 의한 유도속 도를 적분함으로써 다음과 같이 얻게 된다.

$$
\begin{aligned}
& \vec{V}_{\text {wake }}=\frac{\Gamma}{4 \pi} \int_{C} \frac{\vec{d} \vec{l} \times \vec{r}}{r^{3}} \\
& \text { where } \Gamma=-\triangle \phi \\
& \phi_{\text {wake }}=\int_{1}^{2}\left[\frac{\Gamma}{4 \pi} \int_{C} \frac{\overrightarrow{d \vec{l}} \times \vec{r}}{r^{3}}\right] \cdot \vec{t} d s
\end{aligned}
$$

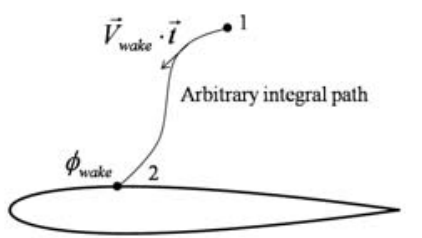

\section{그림 1. 속도장 적분을 통한 후류 포텐셜}

그림 1 과 같이 블레이드 표면의 후류 포텐셜 영 향을 임의의 경로를 통하여 속도 적분으로 얻을 수 있다. 특이성은 와류의 코어모델을 통하여 해 소될 수 있다.

\subsection{3 병렬 계산}

많은 회전수나 작은 시간간격해석을 위해서는 많은 계산시간이 필요하다. 특히 본 시간 전진

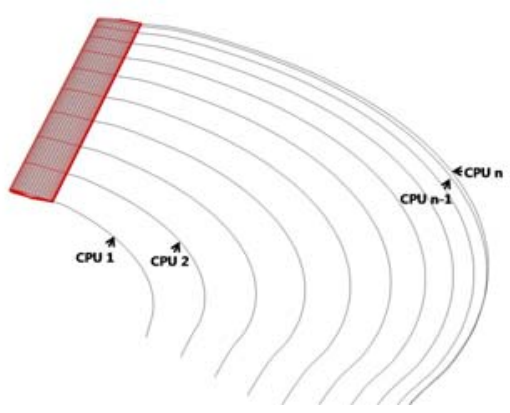

그림 2. 병렬해석을 통한 계산 가속화

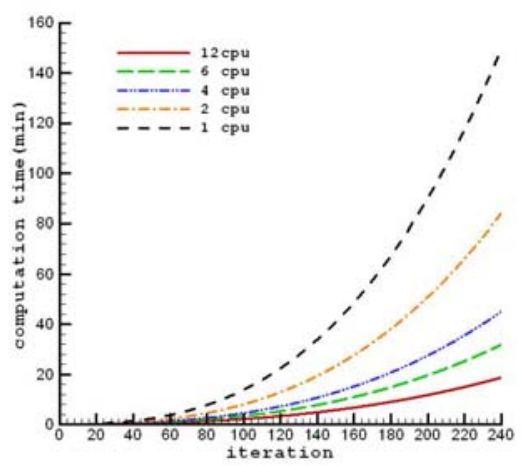

그림 3. $\mathrm{CPU}$ 개수에 따른 계산 시간

자유후류의 경우 매시간 계산해야하는 와선의 개 수가 증가하기 때문에 시간이 지날수록 많은 계 산시간이 필요하게 된다. 이러한 시간 증가를 줄 이기 위하여 본 연구에서는 $\mathrm{MPI}($ Messege Passing Interface)를 이용한 병렬해석을 가능하게 하였다. 병렬해석은 그림 2 와 같이 각 패널에 발생되는 와선을 각 $\mathrm{CPU}$ 에 할당함으로 이루어진다. 즉 후 루 패널이 스팬 방향으로 $\mathrm{n}$ 개 존재할 경우 $\mathrm{n}$ 개 의 $\mathrm{CPU}$ 를 각 스팬에 할당하여 계산을 하게 된 다. 계산 속도는 그림 3 에 알 수 있듯이 $\mathrm{CPU}$ 개수가 증가 할 수록 계산 속도가 증가함을 알 수 있다. 특히 단일 $\mathrm{CPU}$ 와 $\mathrm{CPU} 12$ 개를 이용한 경우와 비교하였을 경우 계산시간이 10 배 정도 빨라짐을 확인 할 수 있다. 이는 많은 회전수나 BVI 계산과 같은 작은 시간간격 해석에 매우 유 리하다.

\section{2 해석결과}

본 논문에서는 제자리 공력 및 익단후류 위치 검증을 통하여 해석 코드의 신뢰성을 확보하고 이를 통하여 BVI 조건에서 나타나는 비정상 하 중을 해석하였다. 


\subsection{1 공력 및 후류 검증}

공력 검증은 Caradonna 와 Tung rotor model[2] 검증을 통하여 이루어 졌다. 해석 조건 은 피치각 12도, 익단 회전 속도는 Mach number 0.664 에서 이루어 졌다. 실험 결과와의 비교는 추력이 수렴이 되는 10 회전이후의 해석결 과와 이루어 졌다. 그림 4 는 10 회전 후 후류 형 상을 와선으로 표현한 그림이다. 그림 5 에서는 압력 실험 결과와 수치결과를 비교하였다. 추력 계수는 0.00796 이며 해석 추력계수는 0.00805 이 었다.

익단 와류 검증에 사용되어진 모델은 $\mathrm{AH}-1 \mathrm{G}$ model[3]로 반지름 $1.0414 \mathrm{~m}$ 인 2 블레이드 로터

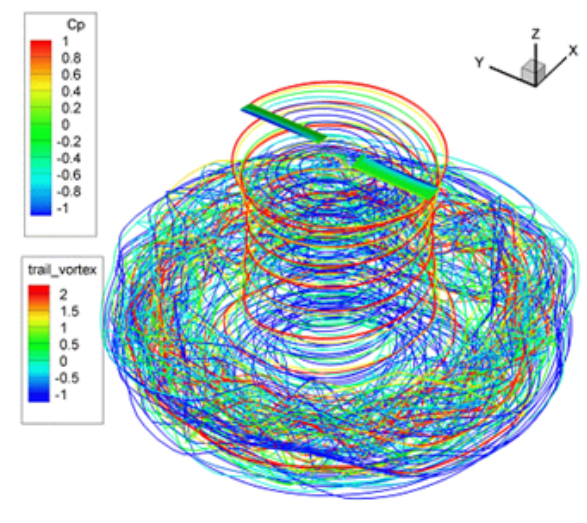

그림 4. 후류 형상

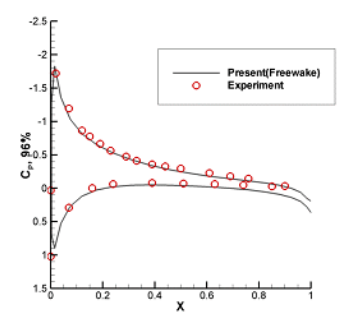

(a) $r / R=0.96$

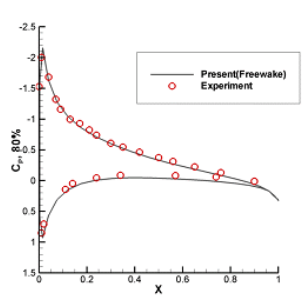

(c) $r / R=0.80$

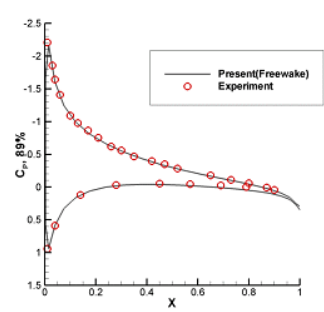

(b) $r / R=0.89$

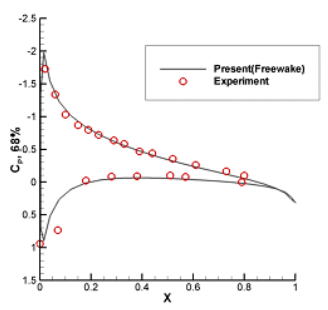

(d) $r / R=0.68$
그림 5. 블레이드 압력계수

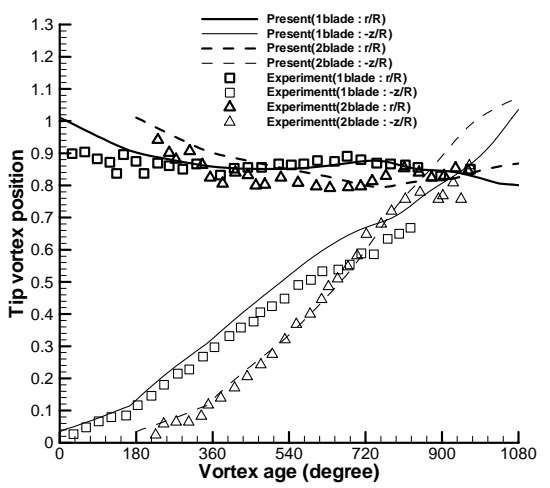

그림 6. 익단 와류 위치[4]

(받음각 11도, 상승속도=3.5ft/s)

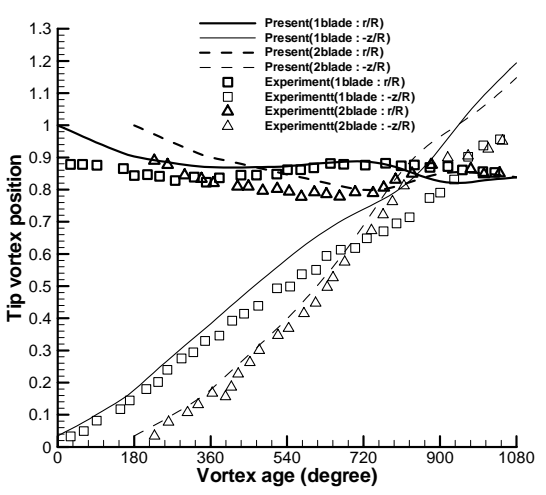

그림 7. 익단 와류 위치[4]

(받음각 11 도, 상승속도 $=9.6 \mathrm{ft} / \mathrm{s}$ )

이다. 해석조건은 RPM 1800 이며, 상승속도 $3.5 \mathrm{ft} / \mathrm{s}$ 이다. 받음각은 12 도에서 해석이 수행되 었다.

총 60 회전을 해석하였으며 각각의 trailed vortex를 병렬 계산하였다. 20회전 후부터 수렴 되어지는 익단와류를 실험값과 비교 하였다. 그 림 6, 7은 수직방향 익단와류 위치 $(-\mathrm{z} / \mathrm{R})$ 와 회전 방향 익단와류 위치 $(\mathrm{r} / \mathrm{R})$ 를 나타낸 그림이다. 비 교적 실험값과 비슷한 결과를 얻음을 확인 하였 다. 익단 와류의 위치는 기준 방위각에서 1080도 사이에서 실험값과 비교 되었다. 그림 6과 7에서 알 수 있듯이 각 블레이드에서 발생된 와류가 방 위각 720 도 부근에서 위치를 교차하는 익단와류 교차 현상을 나타내고 있다.

\subsection{2 $\mathrm{BVI}$ 조건에서의 비정상 하중}

BVI 조건에서 비정상 하중 변화를 살펴보기 위하여 AH-1G 1/7 축소 모델[5]을 해석하였다. 
표 1. Pitch, flapping 계수

\begin{tabular}{|c|c|c|c|c|c|c|}
\hline (unit: degree) & $\theta_{0}$ & $\theta_{1 s}$ & $\theta_{1 c}$ & $\beta_{0}$ & $\beta_{1 s}$ & $\beta_{1 c}$ \\
\hline \hline $\begin{array}{c}\text { Control angle } \\
\text { after trimming }\end{array}$ & 6.7 & -3.9 & 1.8 & 0.5 & 0.0 & -1.0 \\
\hline
\end{tabular}

블레이드는 8.2 도의 비틀림 각을 가지고 있으며 Aspect ratio 9.22 이다. 익단 회전 속도는 Mach number 0.664 이며 전진비는 0.164 이다. 추력 계수 는 0.0054 이다. 또한 tip-path-plane은 뒤로 1 도 기울 어 있다. 로터해석은 Newton-Rhapson iteration 트 림해석을 통하여 pitch 각과 flapping 각이 정하 여 졌다. 표 1은 트림해석을 통한 조종 각 계수 를 나타낸 그림이다. 조종 각은 식 9,10 에 의해 서 정의된다.

Pitch angle: $\theta=\theta_{0}+\theta_{1 s} \sin \psi+\theta_{1 c} \cos \psi$

Flapping angle: $\beta=\beta_{0}+\beta_{1 s} \sin \psi+\beta_{1 c} \cos \psi$

트림해석 시에는 10 도 간격으로 계산하였으며 트 림 해석 하였다. 그림 8은 로터 후류와 블레이드 표면 압력을 나타내고 있다. 그림에서 익단 와류 가 블레이드와 직접적으로 간섭하고 있음을 알 수 있다. 그림 9 에서와 같이 해석간격을 12 도, 8 도, 4 도, 2 도에서 수행하여 공력의 수렴성을 확 인하고 해석 시에는 1 도 간격으로 $\mathrm{BVI}$ 해석을 수행하였다.

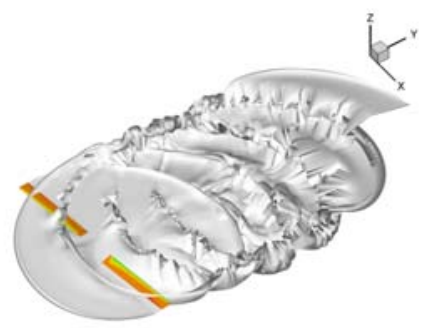

그림 8. $\mathrm{BVI}$ 조건에서의 공력 및 후류

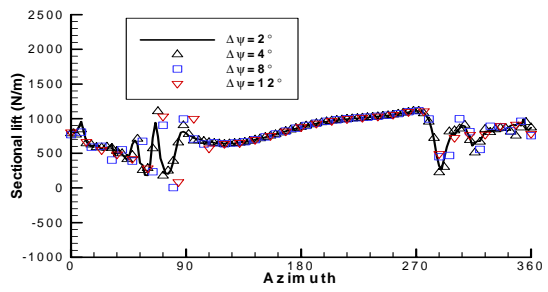

그림 9. 시간간격에 따른 비정상 공력 $(\mathrm{r} / \mathrm{R}=0.955$ 에서의 단면 하중)

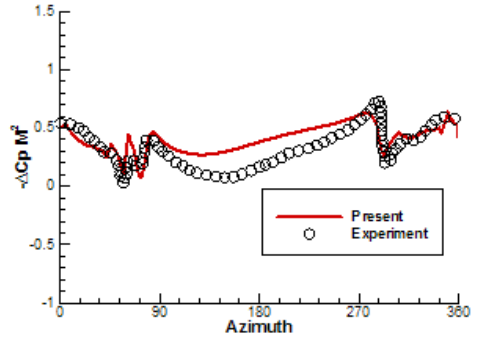

a) $r / R=0.975$

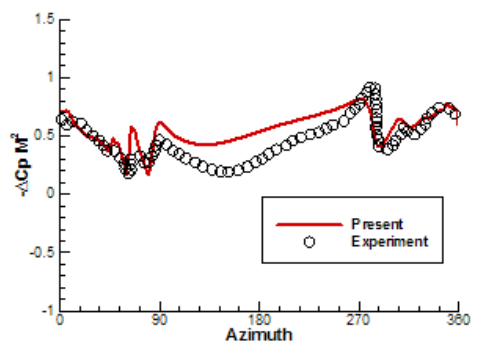

b) $r / R=0.91$

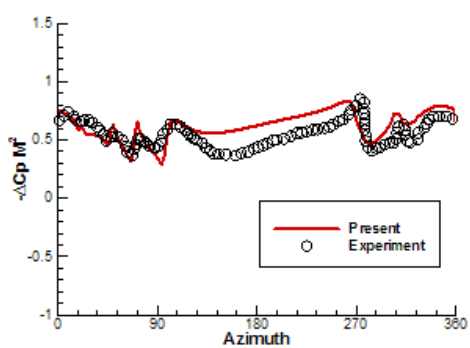

c) $r / R=0.8$

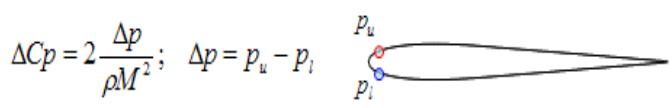

그림 10. 압력 계수 차이 변화

그림 10 은 코드 위치 $x /$ chord $=0.03$ 위치에서의 에어포일 윗면과 아래면의 압력 차이를 나타낸 그림이다. 그림 11은 단면 양력을 나타낸 그림이 다. 공력 결과들은 실험값과 다른 유동해석 결과 [6]와 비교하였다. 그림에서 알 수 있듯이 전진부 90도 근처에서 강한 BVI 가 나타남을 확인할 수 있다. 또한 후퇴부 270도 근처에서도 BVI가 나타 남을 확인할 수 있다. 그림 11 에서 본 해석 결과 가 다른 결과에 비하여 전진부에서 크게 나타남 은 와류의 강도가 더블렛 패널에 직접적으로 반 영됨에서 기인한다. 또한 후퇴부 근처에서의 하 중이 다른 결과와의 차이는 트림 해석을 통한 피 치각의 변화에 의함을 유추할 수 있다. 그림 12 는 1 회전동안의 단면추력을 회전면에 나타낸 그 림이다. 회전각에 따른 공력변화를 확인 할 수 있다. 특히 익단와류에 위치에 따른 단면 변화를 


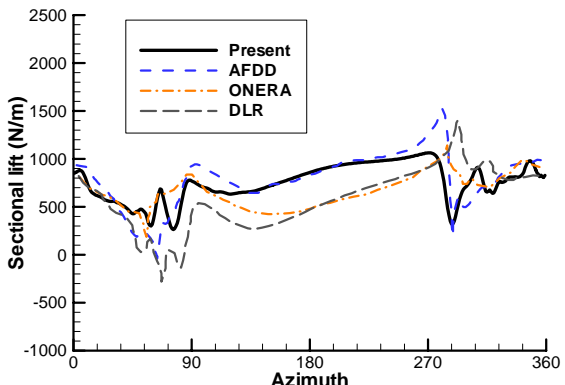

a) $r / R=0.955$

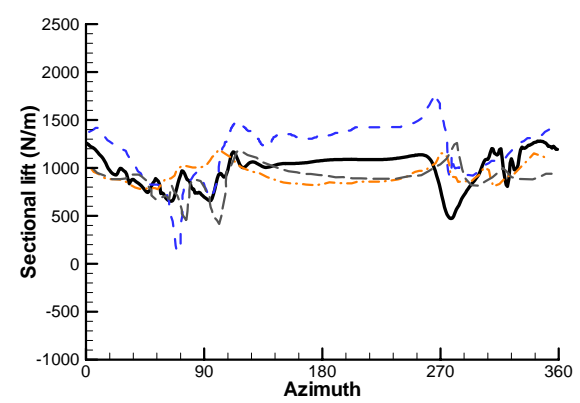

b) $r / R=0.8$

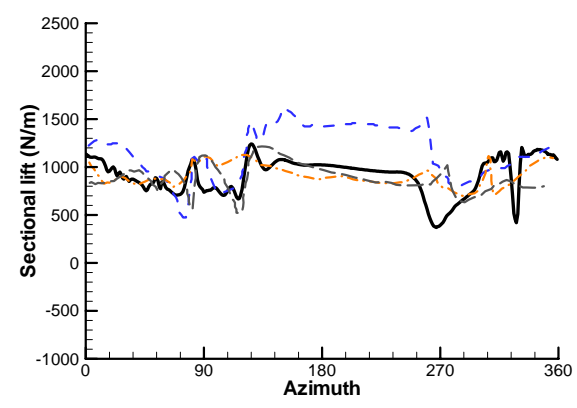

c) $r / R=0.7$

그림 11. 단면 하중 변화

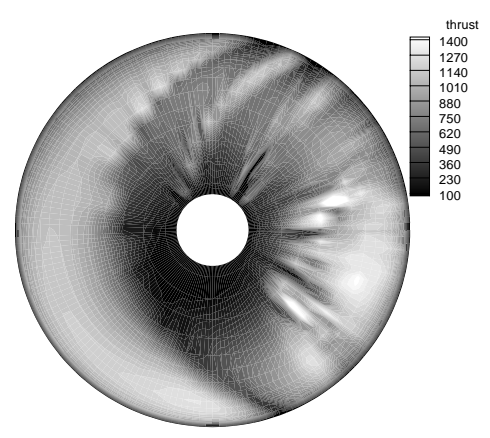

(a) 하중 분포 (해석 결과)

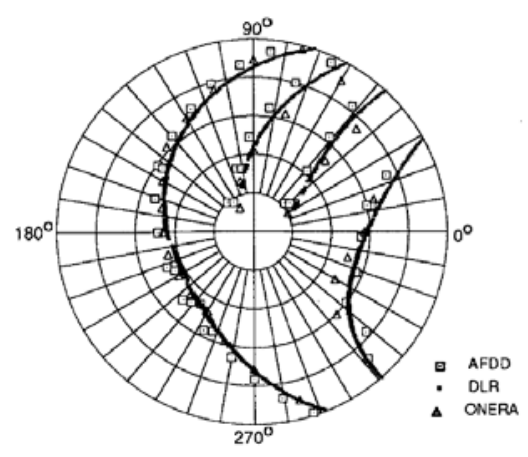

(b) 익단 와류 위치 [6]

그림 12. 하중 분포

정성적으로 확인 할 수 있다. 실험 익단와류 위 치와 비슷한 형태로 추력 등고선이 나타나고 있 음을 알 수 있다.

\section{III. 결 론}

본 연구에서는 BVI 조건에서의 비정상 하중을 예측하기 위하여 저속 전진 비행을 해석하였다. BVI 조건에서는 해석 시 전진 부와 후퇴 부 근 처에서 블레이드 표면의 공력이 급격히 변화함을 단면 하중변화를 통하여 확인할 수 있었다. 또한 익단와류에 의한 하중변화임을 정성적으로 알 수 있었다. 본 논문에서는 이러한 비정상 공력 변화 를 비정상 패널법과 시간전진 자유후류를 통하여 파악 하였다.

\section{참고문헌}

1) Gennaretti, M., Bernardini, G. "Novel Boundary Integral Formulation for Blade-Vortex Interaction Aerodynamics of Helicopter Rotors", AIAA Journal, Vol. 45, No. 6, 2007, pp. 1169 1176.

2) Caradonna, F. X. and Tung, C., "Experimental and Analytical Studies of a Model Helicopter Rotor in Hover", NASA TM-81232, 1982.

3) Caradonna, F., Hendley, E., Silva, M., Huang, S., Komerath, N., Reddy, U. Mahalingam, R., Funk, R., Ames R., Darden, L., Villareal, L., Gregory, and Wong, O., "An Experimental Study of a Rotor In Axial Flight", 
AHS Specialists' Meeting on Aerodynamics and Aeroacoustics, Williamsburg, VA, Oct. 1997.

4) Wie, S. Y., Lee, S. and Lee, D. J., "Potential-Based Panel and Time-Marching Free-Wake Coupling Analysis for Helicopter Rotor Aerodynamics and Wake", submitted to Journal of Aircraft, 2008.

5) Splettstoesser, W. R., Schultz, K. J., Boxwell, D. A., and Schmitz, F. H., "Helicopter Model Rotor-Blade Vortex Interaction Impulsive Noise: Stability and Parametric Variations", 10th ERF, Netherlands, 1984.

6) Yu, Y. H., Tung, C., Gallman, J., Schultz, K. J., van der Wall, B., Spiegel, P., and
Michea, B., "Aerodynamics and Acoustics of Rotor Blade-Interaction", Journal of Aircraft, Vol. 32, No. 5, 1995, pp. 970-977.

7) Chung, K. H., Na, S. U., Jeon, W. H. and Lee, D. J., "Numerical Prediction of Roll-Up Phenomena at Vertical Flight Using A Time-Marching Free Wake Method.", KSAS International Journal, Vol. 1, No. 1, 2000.

(8) 유기완, 나선욱, "정지 비행시 로터 후류 모형 비교 검토", 한국항공우주학회지, Vol. 25, No. 4, 1997.

(9) 이재원, 이관중, 오세종, "비정상 Source-Doublet 패널 기법을 이용한 헬리콥터 로터 공력 해석", 한국 항공우주학회지, Vol. 34, No. 6, 2006. 